Revista Eletrônica de Direito Processual - REDP.

Rio de Janeiro. Ano 11. Volume 18. Número 3. Setembro a Dezembro de 2017

Periódico Quadrimestral da Pós-Graduação Stricto Sensu em Direito Processual da UERJ

Patrono: José Carlos Barbosa Moreira. ISSN 1982-7636. pp. 280-296

www.redp.uerj.br

\title{
PROCESSO CIVL E COMPLEXIDADE ${ }^{1}{ }^{2}{ }^{2}$
}

\section{CIVIL PROCEDURAL LAW AND COMPLEXITY}

\section{Remo Caponi}

Professore Ordinario nell’Università degli Studi di Firenze, Italia. Senior global research fellow New York University. Florença, Itália. remo.caponi@gmail.com

\begin{abstract}
RESUMO: O artigo analisa a qualificação de um processo complexo e o seu relacionamento com os variados meios de tratamento das causas dentro de uma ordem processual individual e coletiva sob a perspectiva do direito italiano e em comparação com outros países da União Europeia.
\end{abstract}

PALAVRAS-CHAVE: Processo complexo. Objeto do processo. Modelos de tratamento da controvérsia. Direito Italiano.

\begin{abstract}
This paper aims to analyze the qualification of a complex process and its relationship among the large variety of case treatment models in an individual lawsuit and class action from the perspective of the Italian Law and in comparative to other countries of the European Union.
\end{abstract}

\footnotetext{
${ }^{1}$ Artigo recebido em 01/08/2017, sob dispensa de revisão.

${ }^{2}$ No original: Processo civile e complessità. Traduzido para o português por Michele Pedrosa Paumgartten, doutoranda em Direito Processual na UERJ, professora de Direito Processual Civil no IBMEC/RJ.

O texto será publicado na Itália em 2018 como parte integrante da obra: CAPONI, R.. Giustizia civile e dogmatica del senso comune. Studi, 2018. O ensaio é inédito nesta produção, sendo resultado da fusão de quatro artigos. O primeiro, Nozione di controversia "complessa": impieghi normativi", foi publicado em Foro italiano, 2009, V, c. 136 ss. e inspirado na intervenção feita no XIX colóquio bienal da Associação Italiana de Direito Comparado, no âmbito da sessão coordenada pelo prof. Michele Taruffo, Aspetti di complessità nelle controversie, Ferrara, 10-12 de maio de 2007. O segundo, Oggeto del processo e del giudicato as assetto variabile, foi publicado em Foro italiano, 2008, V, c. 180, numa reunião de breves intervenções sobre Azione collettiva risarcitoria (art. 140 bis del codice del consumo). O terceiro, Variabilità dell'oggetto del processo (nell'azione collettiva risarcitoria), foi publicada na Rivista di Diritto Processuale, 2009, p. 47, bem como em La conciliazione collettiva, organizado por GITTI, G. E GIUSSANI, A., Milão, 2010 e é a base do relatório da conferência La Conciliazione Collettiva, Università statale di Milano, 26 de setembro de 2008. O quarto, Il principio di proporcionalità nella giustizia civile: risvolti in tema class action, foi publicado em $w w w$.giustamm.it, 2010.
} 
KEYWORDS: Complexity. Object. Case treatment models. Italian Law.

SUMÁRIO: 1. Delimitação do objeto e da investigação. 2. Noção de processo complexo. 3. Noção de controvérsia complexa. 4. Vários modelos de tratamento, apenas um rito. 5. Rigidez da regra processual de cognição italiana. 6. Controvérsia complexa/controvérsia simples como critério de escolha do modelo de tratamento. 7. Controvérsia complexa/controvérsia simples como critério de determinação do objeto do processo. 8 . Tese e antítese. 9. Objeto do processo como direito subjetivo. 10. Interpretação literal do art. 140-bis do código do consumidor. 11. Interesses protegidos. 12. Argumento comparativo. 13. Síntese dialética. 14. A existência além do caso concreto. 15. Não somente "o que", mas também o "porquê", o "como" e o "quando". 16. Argumentação orientada à consequência. 17. Aplicação. 18. Limitação do princípio dispositivo: impugnação e réplica. 19. Comprometimento da condição de terceiro do juiz: impugnação e réplica. 20. Aspectos do princípio da proporcionalidade na justiça civil. 21. Conclusões. 22. Referências bibliográficas.

\section{Delimitação do objeto e da investigação}

Este ensaio não estabelece uma conexão entre a noção de complexidade empregada no processo civil à noção de complexidade empregada em outros ramos do saber. Não é certo que uma operação desse gênero seria frutífera, mas não se pode descartá-la. Aceitase, por conseguinte, a observação deste malogrado nexo como um possível apontamento crítico.

\section{Noção de processo complexo}

No proceso civil italiano o adjetivo "complexo" se refere provavelmente ao substantivo "processo". Este qualifica os processos caracterizados por um acúmulo de demandas e/ou pluralidade de partes. Serve para descrever em modo resumido estes fenômenos, que deduzimos de outras classificações, em primeiro lugar, da "conexão" (da 
Revista Eletrônica de Direito Processual - REDP.

Rio de Janeiro. Ano 11. Volume 18. Número 3. Setembro a Dezembro de 2017

Periódico Quadrimestral da Pós-Graduação Stricto Sensu em Direito Processual da UERJ

Patrono: José Carlos Barbosa Moreira. ISSN 1982-7636. pp. 280-296

www.redp.uerj.br

causa) às suas regras processuais. Tal emprego descritivo do termo "complexo" não interessa neste momento.

\section{Noção de controvérsia complexa}

Interessa selecionar alguns possíveis empregos normativos do adjetivo "complexo" relativo às controvérsias, em uma perspectiva de política legislativa. Emprego normativo no mais simples dos significados: como elemento do caso concreto em que se relacionam efeitos jurídicos no plano da regra processual. Em particular, examinam-se duas possibilidades de emprego:

a) como critério de escolha do modelo de tratamento da causa, dentro de uma ordem procedimental unitária;

b) como critério de determinação do objeto do processo.

\section{Vários modelos de tratamento, apenas um rito}

Nos ordenamentos dos países europeus, a regra do processo ordinário de cognição se articula frequentemente a uma multiplicidade de modelos de tratamento do caso, ajustados sobre as características de uma única controvérsia deduzida em juízo. Os modelos de tratamento se colocam no interior de uma ordem procedimental unitária. A escolha entre um modelo de tratamento e outro é confiada ao juiz, em colaboração com as partes, e está compreendida entre as suas competências na direção formal do processo.

No processo civil inglês, a escolha é entre small claim track, fast track, multi track. No processo civil francês, a escolha é entre circuit court, circuit moyen e circuit long. No processo civil alemão há a escolha de fazer preceder a audiência principal de uma primeira audiência imediata ou de um procedimento preliminar escrito.

A flexibilidade com os quais os vários modelos de tratamento se adaptam às cracterísticas de uma controvérsia única aumenta, se for considerado que o progresso da ordem procedimental é marcado pelos prazos legais, cuja duração é fixada, contudo, em concreto pelo juiz, ou por determinações temporais completamente elásticas. Exemplar o artigo 764 do novo código de processo civil francês, segundo o qual o juiz da mise en ètat fixa os prazos necessários para a instrução da causa, conforme a natureza, a urgência e - 
Revista Eletrônica de Direito Processual - REDP.

Rio de Janeiro. Ano 11. Volume 18. Número 3. Setembro a Dezembro de 2017

Periódico Quadrimestral da Pós-Graduação Stricto Sensu em Direito Processual da UERJ

Patrono: José Carlos Barbosa Moreira. ISSN 1982-7636. pp. 280-296

www.redp.uerj.br

sem dúvida - a complexidade da mesma, depois de ter ouvido os advogados. Exemplares

também são algumas previsões do código de processo civil alemão, segundo as quais "a audiência deve acontecer o mais rápido possível” ( $§$ 272, III ZPO alemão), ou então, a parte deve fazer valer "tempestivamente" os seus meios de ataque e de defesa na audiência ( $§ 282$, I ZPO), além de comunicar "tempestivamente" a outra parte, antes da audiência, os meios de ataque e de defesa, sendo previsível que esta última não possa tomar uma posição sem informação prévia ( $§ 282$, II ZPO).

Portanto, a tendência que está se convalidando a nível europeu é aquela de uma regra elástica de processo de cognição plena, que confia o desenvolvimento no caso concreto, em uma certa medida, às determinações discricionárias do juiz.

\section{Rigidez da regra processual de cognição italiana}

Neste quadro, destaca-se em vários aspectos a maior rigidez das regras do processo civil italiano.

Em primeiro lugar, a técnica seguida na Itália de se relacionar com os diversos tipos de controvérsias não é a multiplicidade dos modelos de tratamento dentro de uma ordem procedimental unitária, mas sim a pluralidade das autonomias procedimentais (ritos especiais em cognição plena ou sumária) que amparam o processo ordinário de cognição. Do contrário, o legislador italiano designou para todos os tipos de controvérsias sujeitas ao rito ordinário, basicamente uma idêntica ordem processual, que admite apenas variantes decisórias, além de medidas antecipatórias de condenação. As fases da sequência são rigorosamente enunciadas na lei detalhadamente.

Em segundo lugar, as margens para as determinações de dicricionariedades do juiz sobre o desenvolvimento formal do processo são muito restritas, considerando que o juiz não pode atribuir prazos sob pena de decadência, exceto nos casos em que a lei expressamente o preveja (art. 152 c.p.c italiano).

\section{Controvérsia complexa/controvérsia simples como critério de escolha do modelo de tratamento}

Um bom compromisso entre as tendências em prática a nível europeu e a atual disciplina do processo civil italiano é constituído por uma virada radical, que sinaliza a 
Revista Eletrônica de Direito Processual - REDP.

Rio de Janeiro. Ano 11. Volume 18. Número 3. Setembro a Dezembro de 2017

Periódico Quadrimestral da Pós-Graduação Stricto Sensu em Direito Processual da UERJ Patrono: José Carlos Barbosa Moreira. ISSN 1982-7636. pp. 280-296

www.redp.uerj.br

passagem dos ritos especiais à diferenciação do rito ordinário "in base alla distinzione trasversale tra controversie complesse e controversie che tali non risultino essere in concreto" (A. Proto Pisani). Serve ao propósito de uma norma que consente ao juiz - em colaboração com as partes - escolher entre duas modalidades de tratamento legislativamente pré-determinadas, alternativas, que dependem da característica simples ou complexa da controvérsia. Nesta acepção, a noção de controvérsia complexa, assim como a de controvérsia simples, é genérica e confiada à determinação concreta do juiz, com base em uma série de parâmetros entre os quais ressaltamos a necessidade de instrução probatória.

\section{Controvérsia complexa/controvérsia simples como critério de determinação do objeto do processo}

Como critério de determinação do objeto do processo, a noção de complexidade poder ser empregada na disciplina da ação coletiva ressarcitória (ou restituitória), introduzida na Itália pelo art. 140-bis do código do consumidor.

Os estudiosos do processo civil atribuem uma importância fundamental à individualização tempestiva do objeto do processo, porque isso retira os propósitos da aplicação de uma série de institutos processuais, como a jurisdição, a competência, a litispendência, etc. , e especialmente para os propósitos de determinação do objeto a ser julgado. Esta consciência é respeitável e conduz a compreender nesta noção uma das portas de acesso ao estudo do processo de cognição como um todo ${ }^{3}$. Não surpreende, portanto, que o aprofundamento deste tema ocupe um papel central na reconstrução da disciplina da ação coletiva ressarcitória.

\section{Tese e antítese}

Opõe-se fundamentalmente duas teses que, com alguma simplificação, podem ser reduzidas basicamente a contraposição que segue.

\footnotetext{
${ }^{3}$ Sobre este ponto v. o clássico estudo de MENCHINI, Sergio. I limiti oggetivi del giudicato civile. Milano: Giuffrè, 1987 e o amplo debate que foi provocado; por último ID., Il Giudicato civile. In: Il diritto. Enciclopedia giuridica. v. VI. Milano: Giuffrè, 2007, p. 687. Cfr. PROTO PISANI, Andrea. Lezioni di diritto processuale civile. 5 ed. Napoli: Jovene, 2006, p. 55.
} 
Revista Eletrônica de Direito Processual - REDP.

Rio de Janeiro. Ano 11. Volume 18. Número 3. Setembro a Dezembro de 2017

Periódico Quadrimestral da Pós-Graduação Stricto Sensu em Direito Processual da UERJ

Patrono: José Carlos Barbosa Moreira. ISSN 1982-7636. pp. 280-296

www.redp.uerj.br

Conforme uma primeira teoria, objeto do processo e de julgamento são unicamente

os créditos ressarcitórios e restituitórios dos consumidores que aderiram à ação coletiva ressarcitória proposta pela associação ou pela comissão, possibilidade que depende do estado das ações para obtenção de uma tutela condenatória.

Segundo a outra teoria, o objeto do processo e do julgamento não são nunca os créditos ressarcitórios e restituitórios dos aderentes, mas algo menor. Dependendo das nuances entre as várias teses, o quid minus é tal a excluir em cada caso a possibilidade de obter uma sentença de condenação para benefício do aderente: o an do direito, a questão relativa à ilicitude da conduta pluriofensiva, a responsabilidade ressarcitória ou restituitória da empresa ou o interesse coletivo dos consumidores e dos usuários.

As duas teses desembocam em soluções quase sempre contrárias a muitos dos problemas práticos levantados pelas novas regras e lançadas deste modo, para perplexidade dos advogados que tem seguido ao menos um dos encontros de estudo já dedicados ao novo instituto. A escolha entre uma e outra tese não é prejudicada em razão da ordem constitucional. Em particular, as teses que veem o objeto do processo e do julgamento na ação coletiva ressarcitória em algo diferente de um direito ou qualquer que seja a situação subjetiva substantiva, não encontram um obstáculo insuperável no art. 24 constitucional ${ }^{4}$. Como outra garantia constitucional, o art. 24, é lançado ao equilíbrio com outros valores constitucionais. Insuperável é apenas o seu conteúdo essencial, que consiste em revelar sempre a tutela jurisdicional dos direitos através de um processo de cognição plena ${ }^{5}$. Isto não exclui a possibilidade de limitar o objeto do processo a uma questão comum a uma série de causas, quando for para obter economia processual e conforme o princípio da proporcionalidade $^{6}$. Este último pode ser ambientado na experiência processual italiana como um resgate do valor constitucional da eficiência na regra processual, que se deduz da afirmação da sua duração razoável (art. 111, parágrafo 2, Constituição).

\footnotetext{
${ }^{4}$ Em sentido contrário, v. contudo DALFINO, Domenico. L'azione collettiva risarcitoria: l'oggetto del processo e del giudicato. Rivista Il Foro Italiano, v. 5, 2008..

${ }^{5}$ É de fato também previsível no nosso sistema a Wesensgehaltsgarantie, o limite do respeito do conteúdo essencial dos direitos (art. 19, parágrafo $2 G G$ alemão e art. 52 da Carta dos Direitos Fundamentais da União Europeia), como "limite do limite". Deste modo, ALEXY, Robert. Theorie der Grundrechte. Frankfurt: Suhrkamp, 1995, p. 267.

${ }^{6}$ O princípio da proporcionalidade é eficazmente insculpido no art. 1 das Rules of civil procedure inglês, em que diz que tratar uma causa com justiça inclui, quando seja possível, entre outras: "atribuir-lhe uma quota adequada dos recursos do juiz, tendo em conta a necessidade de reservar os recursos aos outros casos.".
} 
Revista Eletrônica de Direito Processual - REDP.

Rio de Janeiro. Ano 11. Volume 18. Número 3. Setembro a Dezembro de 2017

Periódico Quadrimestral da Pós-Graduação Stricto Sensu em Direito Processual da UERJ Patrono: José Carlos Barbosa Moreira. ISSN 1982-7636. pp. 280-296

www.redp.uerj.br

\section{Objeto do processo como direito subjetivo}

Aplica-se as experiências jurídicas iniciais, desde que o novo governo não decida procrastinar a obtenção de eficácia das novas disposições. Esta situação interlocutória é propícia para derrubar o cenário tradicional, mas antes de executar esta operação, nos próximos parágrafos manifesto mais uma vez a minha afeição às argumentações tradicionais, favoráveis a um objeto da ação coletiva ressarcitória entendido como direito subjetivo individual dos consumidores aderentes.

\section{Interpretação literal do art. 140-bis do código do consumidor}

Primeiro argumento. Premissa maior: continua-se com algum fundamento para ensinar aos estudantes que o art. 2909 c.c se refere ao direito deduzido em juízo a declaração habitual em todas as sentenças emanadas no fim do processo de cognição plena (mera declaração, condenação ou sentença constitutiva). Acrescente-se que, excepcionalmente, o processo civil pode ter como objeto exclusivamente a declaração de um mero fato juridicamente relevante, de uma questão ou de um ponto de direito.

Dupla premissa menor: o art. 140-bis, parágrafo 1 prevê que o autor proponha formalmente a demanda de "declaração do direito ao ressarcimento do dano e a restituição dos montantes individuais" matérias aderentes a sua iniciativa. Por isso confirma, em via específica e concreta, o conteúdo normativo geral do art. 2909 c.c.. Não obstante se afirme às vezes, que a interpretação literal do art. 140-bis, parágrafo 1 c. cons. beneficia as teses que percebem o objeto do processo exclusivamente na declaração da questão relativa à ilicitude da conduta pluriofensiva do réu.

Conclusão: o art. 140-bis c.cons. é interpretado, desta forma, em sentido contrário ao "senso fatto palese dal significato proprio delle parole secondo la connessione di esse" (art. 12 Preleggi). O que talvez possa ser alinhado com a meta hermeneutica da ciência jurídica contemporânea. Mas em seguida, poderíamos (quase) parar de ler o art. 140-bis e refletir, por assim dizer, "independentemente". 
Revista Eletrônica de Direito Processual - REDP.

Rio de Janeiro. Ano 11. Volume 18. Número 3. Setembro a Dezembro de 2017

Periódico Quadrimestral da Pós-Graduação Stricto Sensu em Direito Processual da UERJ

Patrono: José Carlos Barbosa Moreira. ISSN 1982-7636. pp. 280-296

www.redp.uerj.br

\section{Interesses protegidos}

Segundo argumento. Colocado entre parentesis a previsão de intervenção (supérflua e incongruente), o art. 140-bis coloca os sujeitos lesados diante de uma alternativa fundamental: o exercício da ação de forma individual ou exercitá-la de forma coletiva, conferindo com a adesão, um mandato de representação para a associação ou comissão autora, que então agirá como representante processual voluntário (não como legitimado extraordinário, nem como titular de uma mera ação). Em ambos os casos, o objeto do julgamento são os créditos ressarcitórios e restituitórios dos indivíduos. Em ambos os casos o poder de ação é do indivíduo, embora no segundo caso isso possa ser exercitado apenas por meio de ação por iniciativa da associação. Em ambos os casos o processo pode ser concluído com uma pronúncia definitiva, e por conseguinte, também com sanção condenatória integral. No caso do exercício da ação em forma coletiva, a segunda fase de determinação negocial ou judicial do quantun torna-se necessário apenas se a condenação integral não for possível devido ao estado das ações. Em ambos os casos a tutela dos direitos deduzidos em juízo podem ser assegurados por provimento cautelar seguido de uma execução forçada ${ }^{7}$.

\section{Argumento comparativo}

Terceiro argumento. A análise do direito comparado dos modelos de tutela coletiva confirma que, em matéria de interesses individuais homogêneos, o objeto do processo e do julgamento são os direitos individuais e não a mera questão relativa à ilicitude da conduta pluriofensiva do réu. Isto vale para o litisconsórcio facultativo, para o processo modelo ${ }^{8}$, bem como para a class action estadiunidense. Neste setor, o recurso ao modelo de ação da associação é resultado de uma escolha contingente. A reconstrução da disciplina da tutela processual dos interesses individuais homogêneos não é para ser achatado sobre os

\footnotetext{
7 Por um discurso mais amplo e pelas citações oportunas, cfr.: CAPONI, Remo. Azioni collettive: interessi protetti e modelli processuali di tutela. Rivista di Diritto Processuale, v. 5, n. 5, pp. 1205-1226, set-out, 2008.

${ }^{8}$ No processo modelo ( ou amostra) vem deduzido em juízo um direito individual de um titular único ( ou de uma associação), mas a pronúncia projeta uma eficácia jurídica, em uma certa mistura vinculante, mesmo quando comparados às causas paralelas. O elemento de eficácia vinculante nas comparações das causas paralelas é a linha que distingue o processo modelo do caso piloto. Noordenamento alemção o processo modelo encontrou pela primeira vez a própria disciplina legislativa no código de justiça administrativa ( $\$ 93$ a $V w G O)$. Ainda segundo a nova lei alemã de 2005, relativa às controvérsias no mercado financeiro $(K a p M u G)$, a fase junto à Corte de Apelação é precedido do início das ações individuais.
} 
Revista Eletrônica de Direito Processual - REDP.

Rio de Janeiro. Ano 11. Volume 18. Número 3. Setembro a Dezembro de 2017

Periódico Quadrimestral da Pós-Graduação Stricto Sensu em Direito Processual da UERJ

Patrono: José Carlos Barbosa Moreira. ISSN 1982-7636. pp. 280-296

www.redp.uerj.br

interesses efetivamente supraindividuais, cuja legitimação basicamente exclusiva das associações, mas é, ao contrário, um dado estrutural (pelo menos no segundo subgrupo de casos). Não é casual a abertura aos comitês no art. 140-bis, parágrafo 2 c.cons.: o legislador introduziu oportunamente uma versão de gestão do montante de ações individuais, mal velada pela proteção organizacional do ente.

\section{Síntese dialética}

Neste ponto tento superar a lógica da contraposição entre as duas teses quanto ao objeto do processo. Para realizar esta operação, não coloco de novo em discussão este ou aquele argumento despendido na polêmica. Coloco de novo em discussão a mesma aproximação que geralmente os processualistas enfrentam nestes problemas, às vezes prenúncio de uma difícil comunicação com os estudiosos do direito civil. Tal dificuldade é sempre uma perda, mas não é especialmente na matéria de tutela coletiva ${ }^{9}$, que, como em outras questões ${ }^{10}$, sugere-se quebrar aquelas barreiras mentais, que, como reflexo dos setores científico-disciplinar condicionam frequentemente na Itália as pesquisas e o próprio modo de refletir dos estudiosos.

\section{A outra existência do caso concreto}

Os trës argumentos apresentados anteriormente, assim como aqueles contrapostos, consideram o objeto do processo e do julgamento exclusivamente de um ponto de vista estrutural. Esses consideram o problema resolvido, sol que se identifica com um suficiente grau de precisão ao que o autor deduziu em juízo: um direito substancial ou uma mera questão? Os dois pontos de vista contrapostos são unidos por uma notável abstração. Em ambos os casos se movem no plano da teoria do caso concreto, tanto que a alternativa pode ser assim reformulada: objeto do processo é um efeito jurídico ou um elemento do caso concreto?

\footnotetext{
${ }^{9}$ Cfr.: CAPONI, Remo. Modelli europei di tutela collettiva nel processo civile: esperienze tedesca e italiana a confronto. Rivista Trimestrale di Diritto e Procedura Civile, v. iv, pp. 1229-1256, 2007.

${ }^{10}$ Um outro tema que se delinea nesse contexto é a incidência da autonomia privada na disciplina do processo civil, cuja disciplina da ação coletiva ressarcitória Un altro tema che si inscrive in questo contesto è l'incidenza dell'autonomia privata nella disciplina del processo civile, con cui la disciplina dell'azione collettiva risarcitoria apresenta não surpreendentemente pontos de contatos: pensa-se a qualificação da relação entre o proponente os aderentes da ação. Cfr.: CAPONI, Remo. Autonomia privata e processo civile: gli accordi processuali. Rivista Trimestrale di diritto e procedure civile, pp. 99-120, 2008.
} 
Revista Eletrônica de Direito Processual - REDP.

Rio de Janeiro. Ano 11. Volume 18. Número 3. Setembro a Dezembro de 2017

Periódico Quadrimestral da Pós-Graduação Stricto Sensu em Direito Processual da UERJ

Patrono: José Carlos Barbosa Moreira. ISSN 1982-7636. pp. 280-296

wWW.redp.uerj.br

Por outro lado, tenho mencionado a dificuldade que encontra a estática

reconstrução do objeto do processo dentro da teoria do caso concreto para enquadrar a concreta dinâmica da atividade protetiva ou lesiva dos interesses humanos ${ }^{11}$. Tais reconstruções afastam frequentemente a ideia de objeto do processo daquela realidade contingente e concreta que o autor hic et nunc submete ao juízo. Em uma palavra, tais reconstruções afastam a teoria jurídica da existência, mas "cerca a sua volta di insinuarsi nel diritto, di penetrare in strutture dalle quali si era voluto tenerla lontana, di prendere stabile possesso di aree che si volevano ad essa precluse" ${ }^{\text {"12 }}$. Tal concessão é, portanto, para integrar ou corrigir com outros critérios, que encurtam esta distância, como a reavaliação da noção empírica chiovendiana de "bem da vida", ou seja, a abertura no sentido da noção de objeto do processo própria da experiência jurídica alemã, que segundo a opinião majoritária, baseia-se sobre hic et nunc da pretensão, assim como especificado no processo desde o pedido de tutela conectada à descrição da situação da vida ${ }^{13}$.

Ponto de partida é adquirir plenamente a consciência que comprimir o objeto do processo dentro da teoria do caso concreto é um defeito, que não é devido ao confronto remoto doutrinário ocorrido nos primeiros comentários ao art. 140-bis c.cons..

\section{Não somente "o que", mas também o "porquê", o "como" e o "quando"}

Provavelmente tal aspecto crítico tem ganhado pela primeira vez de modo incisivo o centro das atenções judiciária italiana no caso Gubisch c. Palumbo ${ }^{14}$. A mudança de perspectiva expressa em passagem do julgamento citado na precedente nota de rodapé de página é de uma simplicidade apaziguadora, quase um "ovo de Colombo". Isso pode

\footnotetext{
${ }^{11}$ Cfr.: CAPONI, Remo. Azione di nullità (profili di teoria generale). Rivista di Diritto Civile. Supplemento n.1/2008, pp. 59-108, 2008.

${ }^{12}$ Assim, RODOTÀ, Stefano. La vita e le regole. Milano: Giuffrè, 2004, passim e p. 25.

${ }^{13}$ Cfr.:ROSENBERG, Leo; SCHWAB, Karl Heinz; GOTTWALD, Peter. Zivilprozessrecht. München: C.H. Beck, 2004, p. 1062.

${ }^{14}$ Corte de Justiça da Comunidade Europeia, 8 de dezembro de 1987, n. 144/86, in Foro it., 1988, IV, c. 341: "quando si tratta in particolare, come nel caso di specie, della vendita internazionale di beni mobili materiali, ne risulta che la domanda di esecuzione del contratto è volta a renderlo efficace, e che la domanda di annullamento e di risoluzione è volta appunto a negargli ogni efficacia. La forza obbligatoria del contratto si trova pertanto al centro delle due controversie. Se la domanda di annullamento o di risoluzione è la domanda posteriore, essa può addirittura essere considerata un semplice mezzo di difesa contro la prima domanda presentata in forma di azione autonoma dinanzi ad un tribunale di un altro Stato contraente. Stando così le cose dal punto di vista processuale è giocoforza constatare che le due controversie hanno il medesimo oggetto, dato che quest'ultima nozione non può essere ristretta all'identità formale delle due domande.". Sobre o ponto de vista, verificar a nítida observação de CONSOLO, Claudio. Profili della litispendenza internazionale. Rivista del Diritto Internazionale. Milano: Giuffrè, 1997, p. 5/ 21.
} 
Revista Eletrônica de Direito Processual - REDP.

Rio de Janeiro. Ano 11. Volume 18. Número 3. Setembro a Dezembro de 2017

Periódico Quadrimestral da Pós-Graduação Stricto Sensu em Direito Processual da UERJ

Patrono: José Carlos Barbosa Moreira. ISSN 1982-7636. pp. 280-296

www.redp.uerj.br

ser sintetizado em uma máxima que se aperta no punho de uma mão: se é importante saber

o que o autor reivindica em juízo, ainda mais importante é saber porquê, como e quando reivindica. Assim pode entrar no processo da vida, recordando felizmente a noção chiovediana e as expressões alemãs Lebenssachverhalt ou Lebensvorgang.

Assim, a declaração judicial pode assumir as conotações de um "prisma" no qual se reflete a existência humana, antes do ordenamento de direito substancial. Assim se pode recuperar a correlação das avaliações entre direito privado e direito processual civil, que impede uma utilização abusiva do processo ${ }^{15}$. Não se trata de uma abertura indiscriminada no sentido de relevar os motivos subjetivos e individuais que fundamentam a iniciativa $\operatorname{litigiosa~}^{16}$, mas sim, de uma abertura calibrada em direção ao escopo objetivo em que a situação concreta em que se econtra o sujeito, sustenta a sua ação judicial. Uma consideração meramente estrutural, estática, rígida, atemporal do objeto do processo, um esforço destinado apenas a responder a pergunta relativa a "o que" é deduzido em juízo em termos de teoria do caso concreto, independentemente da condição fatual e da expectativa do autor e do réu, perdendo o contato com a realidade substancial de milhares de facetas, de milhares de mudanças de cores. É difícil deixar o "porquê", o "como" e o "quando" integralmente fora da teoria do objeto do processo.

\section{Argumentação orientada à consequência}

Quid iuris do discurso feito nos parágrafos anteriores? Música do futuro? Não, embora se natura non facit saltus. Limito provisoriamente a avaliação do seu impacto prático à polêmica em matéria de objeto da ação coletiva ressarcitória.

A primeira consequência é a de desistir de confrontar de novo literalmente os argumentos sustentados de uma ou outra tese sobre o objeto do processo, especialmente aqueles que se fundam essencialmente na leitura do texto do art. 140-bis c. cons. Sob a pressão da urgência de prover, determinada por um enredo parlamentar rocambolesco, contorna-se muito bem sob os nossos olhos a entrada em vigor de uma obra legislativa aberta, que torna plausíveis as teses opostas. Desejávamos uma lei mais clara, mas neste

\footnotetext{
${ }^{15}$ Por um amplo discurso, v. Divieto di frazionamento giudiziale del credito: applicazione del principio di proporzionalità nella giustizia civile? Rivista Il Foro Italiano, I, 2008., em nota a Cass. n. 23726 del 2007.

${ }^{16}$ Além disso, tal abertura é uma peculiaridade vantajosa da conciliação como métdo negocial de composição das controvérsias. Cfr.: LUISO, Francesco. Conciliazione, in: Il diritto. Enciclopedia giuridica, v. III. Milano: Giuffrè, 2007, p. 498.
} 
Revista Eletrônica de Direito Processual - REDP.

Rio de Janeiro. Ano 11. Volume 18. Número 3. Setembro a Dezembro de 2017

Periódico Quadrimestral da Pós-Graduação Stricto Sensu em Direito Processual da UERJ

Patrono: José Carlos Barbosa Moreira. ISSN 1982-7636. pp. 280-296

www.redp.uerj.br

ponto, trata-se de fazer "por necessidade, vontade", segundo a sabedoria popular, e assim individualizar um critério racional de escolha entre teses opostas, parâmetros plausíveis. Tal critério é a consideração das implicações práticas que a escolha interpretativa presumidamente produz ao externo. Em suma, estamos diante de um quadro normativo, em grau de receber e oferecer um fundamento de interpretações simplesmente orientada à consequência $^{17}$. Na presença de um texto (mal) concebido, deslocamos, assim, o debate sobre a letra da lei ao juízo de valor da consequência que com base na plataforma autoritária, pretendemos alcançar.

\section{Aplicação}

Alguns exemplos de aplicação, obviamente sem a pretensão de elaborar uma lista exaustiva. Primeiro exemplo. O ilícito pluriofensivo consiste em um idêntico serviço fornecido sem pedido do profissional a uma pluralidade de usuários. Pelo serviço foi pago um montante idêntico. Da declaração de ilicitude da conduta do réu surge automaticamente a determinação da soma a restituir. É merecedor de ser suportada (e conforme a garantia constitucional da efetividade da tutela jurisdicional) uma interpretação orientada a conseguir oferecer aos aderentes individuais da ação, um título executivo ao final do processo coletivo. Esta interpretação é compatível com o texto do art. 140-bis c.cons., parágrafo 4 , item 2 . A soma mínima determinada pelo juiz é na realidade, neste caso, a soma total. A lei não menciona o caráter condenatório da sentença, mas nem mesmo o art. 474 c.p.c o menciona ${ }^{18}$.

Segundo exemplo. O ilícito pluriofensivo consiste na produção e venda de um produto nocivo para a saúde humana, mas a declaração do an e do quantum do dano imediatamente de cada consumidor depende de um juízo individualizado, adaptado para as circunstâncias que determinaram o dano no caso individual. É merecedor de ser suportada ( conforme o princípio de eficiência da justiça civil, e não só ao princípio da paroporcionalidade) uma interpretação orientada à consequência de excluir a possibilidade de empregar o processo coletivo no juízo individualizado relativo a um ou mais dos

\footnotetext{
${ }^{17}$ MENGONI, Luigi. Ermeneutica e dogmatica giuridica. Milano: Giuffrè, 1996, p. 91.

${ }^{18}$ Caso contrário, em caso concreto como este, passa-se a forçar a ação inibitória ex art. 140 c. cons. Para um melhor entendimento, v. CAPONI, Remo. Una letteratura di interrogativi in attesa della giurisprudenza. Rivista Il Foro Italiano, v. 5, 2008.
} 
Revista Eletrônica de Direito Processual - REDP.

Rio de Janeiro. Ano 11. Volume 18. Número 3. Setembro a Dezembro de 2017

Periódico Quadrimestral da Pós-Graduação Stricto Sensu em Direito Processual da UERJ

Patrono: José Carlos Barbosa Moreira. ISSN 1982-7636. pp. 280-296

www.redp.uerj.br

direitos cumulados ${ }^{19}$. Esta interpretação é compatível com o texto do art. 140-bis, parágrafo 4, item 2 c.cons., na parte em que se prevê que o juiz determinará a soma mínima apenas se isso for possível dependendo do estado da ação. Objeto do processo e do julgamento é, neste caso, a questão comum e relevante à ilicitude da conduta da empresa $\mathrm{ré}^{20}$.

Terceiro exemplo. A audiência de definição das conclusões no juízo de apelação comunica algumas novas adesões à ação coletiva ressarcitória referida no primeiro exemplo, com muitas datas diferentes de estipulação contratual, algumas remontando vários anos atrás. $\mathrm{O}$ ponto de equilíbrio entre a previsão de um canal sempre aberto à adesão e o direito de defesa do réu é que o processo coletivo veda basicamente como objeto do seu debate as questões comuns, segundo a técnica do processo modelo, e que se conclui com uma sentença declaratória ou mesmo com uma sentença condenatória, em ambos os casos sem prejuízo às exceções pessoais ${ }^{21}$.

\section{Limitação do princípio dispositivo: impugnação e réplica}

O segundo exemplo formulado no parágrafo anterior, merece um aprofundamento. Analisando a solução nela proposta, apresenta-se uma objeção: a escolha judicial entre modelos alternativos de objeto do processo limita-se a um aspecto fundamental do princípio dispositivo em sentido substancial, que é o domínio da autonomia das partes, não apenas na determinação do início e fim do processo, mas também do seu objeto. A objeção é séria e força uma réplica articulada.

Em primeiro lugar, examinar a incidência do princípio dispositivo no processo civil não equivale a debater o eterno retorno do mesmo. No panorama europeu, a incidência do princípio dispositivo não é idêntica nos variados ordenamentos. O elemento em que se registra mais facetas é provavelmente aquele relativo à delimitação do objeto do processo e do julgamento. Passa-se da restrita solução alemã, em cujo objeto do processo e do

\footnotetext{
19 A solução posta pode ser tomada em consdeiração apenas na presença de uma evolução do direito substancial no sentido da relevância da evidência epistemológica e/ou estatística na avaliação do nexo causal, que o transforará em uma questão essencialmente comum.

20 Esta variação pode encontrar uma paraelo na - enquanto contrastada - experiência norteamericana da issue class action, sobre a qual tem chamado recentemente a atenção GIUSSANI, Andrea. Azioni collettive risarcitorie nel processo civile. Bologna: Il Mulino, 2008.

${ }^{21}$ Cfr.:CONSOLO, Claudio; BONA, Marco; BUZZELLI, Paolo. Obiettivo class action: l'azione risarcitoria collettiva. Giuffrè: Milano, 2008, p. 215 ss.
} 
Revista Eletrônica de Direito Processual - REDP.

Rio de Janeiro. Ano 11. Volume 18. Número 3. Setembro a Dezembro de 2017

Periódico Quadrimestral da Pós-Graduação Stricto Sensu em Direito Processual da UERJ Patrono: José Carlos Barbosa Moreira. ISSN 1982-7636. pp. 280-296

www.redp.uerj.br

julgamento é delimitado pelo pedido da parte, individualizada através dos fatos alegados, à solução intermediária italiana, em que a lei, e não só a vontade das partes, pode contribuir à determinação objetiva do julgamento (art. 34 c.p.c) para alcançar a ampla solução inglesa, que pode impedir qualquer nova consideração dos fatos objeto da decisão judicial. $\mathrm{O}$ art. 34 c.p.c permite uma extensão do objeto do processo às questões prejudiciais (logo uma limitação à autonomia da parte) ditada por razões de economia e eficiência da tutela jurisdicional, avaliada de modo geral e abstrata pelo legislador. A solução proposta no parágrafo anterior em relação ao segundo exemplo, permite uma extensão (ou ainda, uma restrição) do objeto do processo coletivo ressarcitório ditada em razão da economia e eficiência da tutela jurisdicional, avaliada em concreto pelo juiz.

Em ambos os casos o princípio dispositivo é limitado por razões relacionadas ao funcionamento do processo, que no segundo caso não são certamente muito frágeis. Ao contrário: o princípio da proporcionalidade no emprego de recurso da administração judiciária sugere configurar a disciplina da causa em série de massa ao êxito de um equilíbrio de valores constitucionais, que coloca sobre um prato da balança a garantia constitucional que apoia o modelo tradicional de tutela jurisdicional dos direitos no processo individual, e sobre o outro prato, a eficiência da administração da justiça, que apoia a tutela jurisdicional dos direitos no conjunto de processos ou em uma classe deles.

\section{Comprometimento da condição de terceiro do juiz: impugnação e réplica}

Contra este raciocínio, propõe-se a seguinte objeção final: a problemática não é tanto a limitação do princípio dispositivo em si, quanto o fato que essa seja confiada à avaliação e escolha do juiz no caso concreto. Isto prejudicará a garantia constitucional da imparcialidade do juiz. Embora esta objeção seja passível de exposição em uma réplica, o que permite a confirmação da solução proposta. A previsão de um aumento dos poderes do juiz é frequentemente acompanhada do relevo crítico que tal aumento ameaça ou pode minar a sua imparcialidade. Isso aconteceu em particular com a previsão dos poderes instrutórios de ofício do juiz. Embora possa ser que para o exercício do poder de delimitar o objeto do processo (dependendo do caráter simples ou complexo da controvérsia coletiva ressarcitória) se pague algum leve preço em termos de imparcialidade psicológica do juiz, como parte desse equilíbrio de valores constitucionais que deve se inspirar a disciplina da 
Revista Eletrônica de Direito Processual - REDP.

Rio de Janeiro. Ano 11. Volume 18. Número 3. Setembro a Dezembro de 2017

Periódico Quadrimestral da Pós-Graduação Stricto Sensu em Direito Processual da UERJ

Patrono: José Carlos Barbosa Moreira. ISSN 1982-7636. pp. 280-296

www.redp.uerj.br

tutela coletiva jurisdicional, mas que esse preço não seja superior àquele associado ao exercício dos poderes instrutórios de ofício e mereça ser pago.

Em concreto, isso significa essencialmente:

a) se o autor delinea o objeto do processo em termos mais restritos que eficientes (p. ex., no primeiro exemplo do parágrafo $\mathrm{n}$. 17 , limita o objeto do processo à questão relativa á ilicitude da conduta do réu), o juiz extrai a questão de ofício e, no caso de inércia das partes, estende o objeto do processo aos créditos restituitórios individuais;

b) se o autor delinea o objeto do processo em termos mais amplos do que eficientes (p. ex., no segundo exemplo do parágrafo n. 17, estende o objeto do processo aos créditos ressarcitórios individuais), o juiz extrai a questão de ofício e, em caso de inércia das partes, limita o objeto do processo à questão relativa à ilicitude da conduta do réu.

\section{Aspectos do princípio da proporcionalidade na justiça civil.}

O inteiro discurso feito até este ponto convida para a elaboração de uma "bússola conceitual" capaz de orientar o intérprete em direção a um ponto de equilíbrio entre a proteção dos interesses individuais de quem age ou se defende no processo individual e os interesses, considerados em conjunto, daqueles que são terceiros em relação ao caso processual individual, isto é, dos outros usuários potenciais ou atuais do serviço de justiça, interesses que se direcionam a uma gestão eficiente do conjunto dos processos. Pressupõese percorrer com cautela esta estrada, colocando em jogo primeiramente um dos critérios cardinais de orientação no exercício dos poderes públicos, que é o princípio da proporcionalidade, de matriz europeia, do qual devemos novamente explorar plenamente a sua potencialidade axiológica e deontológica no campo da justiça (mais adiante, ao menos de iure, é o mais geral campo da administração pública). Isso é eficazmente esculpido no art. 1 das Rules of civil procedure inglesas (1997), onde se diz que tratar uma causa de forma justa inclui, por quanto seja possível, entre outros: “attribuire ad essa una quota appropriata delle risorse del giudice, tenendo conto della necessità di riservare le risorse agli altri casi”. Esta norma se inspira no art. 0.8 (Eficiência no processo civil) dos princípios fundamentais dos processos jurisdicionais no projeto de novo código de processo civil redigido por Andre Proto Pisani: “È assicurato un impiego proporzionato delle risorse giudiziali rispetto allo scopo della giusta composizione della controversia 
Revista Eletrônica de Direito Processual - REDP.

Rio de Janeiro. Ano 11. Volume 18. Número 3. Setembro a Dezembro de 2017

Periódico Quadrimestral da Pós-Graduação Stricto Sensu em Direito Processual da UERJ

Patrono: José Carlos Barbosa Moreira. ISSN 1982-7636. pp. 280-296

www.redp.uerj.br

entro un termine ragionevole, tenendo conto della necessità di riservare risorse agli altri

processi". Assim entendido, o princípio da proporcionalidade pode ser ambientado na experiência processual italiana como um aspecto de valor constitucional da eficiência na disciplina do processo, que se deduz da afirmação da duração razoável (art. 111, parágrafo 2 Cost.)

O princípio da proporcionalidade no emprego dos recursos judiciais sugeriu a configuração da disciplina do processo coletivo, no novo texto do art. 140-bis c.cons. como resultado de um equilíbrio de valores constitucionais que coloca sobre um prato da balança as garantias que apoiam o modelo tradicional de tutela jurisdicional dos direitos no processo individual, e sobre outro prato, a absorção dentro de um único processo complexo, uma variedade de controvérsias seriais. Uma escolha que relaciona a solução adotada no processo individual à gestão do conjunto dos processos, neste caso de uma classe deles. Mas se deve tratar somente do primeito passo de um caminho muito longo, elucidado pela consideração que, na tutela coletiva, o escopo do processo civil é também, uma mistura apreciável, a regulação concreta, bem como o controle, das condutas sociais e econômicas que incidem sobre os interesses supraindividuais ou sobre os interesses individuais homogêneaos (escopo tradicionalmente confiado aos organismos administrativos e ao sistema de sanção penal). Se considerarmos este escopo como um ponto estacionário, as variáveis dependentes não podem tornar-se os elementos do modelo processual tradicional e os papeis dos protagonistas do caso processual. O problema se torna então: quais renúncias, quais alterações devemos enfrentar para realizar aquele objetivo? Nesta perspectiva, apenas como um exemplo, o mesmo mecanismo de opt out poderá ser considerado menos escandaloso, ao menos para as controvérsias de pequenas causas, do que estaria inclinado a considerá-lo atualmente.

Progredir a consciência de que o opt out não enconta obstáculos de ordem constitucional, menos ainda nesse setor das controvérsias de pequenas causas (small claims), ou melhor, no setor das controvérsias que tem um valor baixo que não chamam a atenção das cortes a não ser de modo agregado, através do exercício de uma ação coletiva.

\section{Conclusões}

Em ambas as utilizações normativas examinadass, a noção de "complexidade" depende principalmente dos perfis relacionados ao estabelecimento dos fatos relevantes. A 
Revista Eletrônica de Direito Processual - REDP.

Rio de Janeiro. Ano 11. Volume 18. Número 3. Setembro a Dezembro de 2017

Periódico Quadrimestral da Pós-Graduação Stricto Sensu em Direito Processual da UERJ

Patrono: José Carlos Barbosa Moreira. ISSN 1982-7636. pp. 280-296

www.redp.uerj.br

escolha entre os modelos de tratamento dependerá frequentemente da necessidade de instrução probatória. A escolha entre os modelos de objeto do processo coletivo ressarcitório dependerá quase que invariavelmente da necessidade ou ao menos da realização de um juízo individualizado por determinar a soma para ressacir ou restituir no caso individual. Em particular, a ação coletiva ressarcitória tem um objeto de ordem variável e juridicamente determinável em concreto a depender do caráter simples ou complexo da controvérsia, bem como do escopo objetivamente perseguido pelas partes, e ainda - em sentido muito residual - das condições concretas do desenvolvimento do processo. Uma conclusão que pressupõe o abandono da rígida adesão à ideia de que a identificação tempestiva e imutável do objeto do processo e do julgamento dentro dos esboços da teoria do caso concreto constitui quase o alfa e o ômega do processo civil.

De outro lado, quando a vida se afasta da ideia, é sinal que precisa mudar de ideia.

\section{Referências bibliográficas}

ALEXY, Robert. Theorie der Grundrechte. Frankfurt: Suhrkamp, 1995.

CAPONI, Remo. Autonomia privata e processo civile: gli accordi processuali. Rivista Trimestrale di diritto e procedure civile, pp. 99-120, 2008.

. Divieto di frazionamento giudiziale del credito: applicazione del principio di proporzionalità nella giustizia civile? Rivista Il Foro Italiano, I, 2008.

. Azione di nullità (profili di teoria generale). Rivista di Diritto Civile. Supplemento n.1/2008, pp. 59-108, 2008.

Azioni collettive: interessi protetti e modelli processuali di tutela. Rivista di Diritto Processuale, v. 5, n. 5, pp. 1205-1226, set-out, 2008.

. Modelli europei di tutela collettiva nel processo civile: esperienze tedesca e italiana a confronto. Rivista Trimestrale di Diritto e Procedura Civile, v. iv, pp. 1229-1256, 2007.

. Una letteratura di interrogativi in attesa della giurisprudenza. Rivista Il Foro Italiano, V, 2008.

CONSOLO, Claudio. Profili della litispendenza internazionale. Rivista del Diritto Internazionale. Milano: Giuffrè, 1997.

; BONA, Marco; BUZZELLI, Paolo. Obiettivo class action: l'azione risarcitoria collettiva. Giuffrè: Milano, 2008.

DALFINO, Domenico. L'azione collettiva risarcitoria: l'oggetto del processo e del giudicato. Rivista Il Foro Italiano, V , 2008.

GIUSSANI, Andrea. Azioni collettive risarcitorie nel processo civile. Bologna: Il Mulino, 2008.

LUISO, Francesco. Conciliazione, in: Il diritto. Enciclopedia giuridica, v. III. Milano: Giuffrè, 2007.

MENCHINI, Sergio. I limiti oggetivi del giudicato civile. Milano: Giuffrè, 1987.

. Il Giudicato civile. In: Il diritto. Enciclopedia giuridica. v. VI, Milano: Giuffrè, 2007.

MENGONI, Luigi. Ermeneutica e dogmatica giuridica. Milano: Giuffrè, 1996.

PROTO PISANI, Andrea. Lezioni di diritto processuale civile. 5 ed. Napoli: Jovene, 2006.

RODOTÀ, Stefano. La vita e le regole. Milano: Giuffrè, 2004.

ROSENBERG, Leo; SCHWAB, Karl Heinz; GOTTWALD, Peter. Zivilprozessrecht. München: C.H. Beck, 2004. 